\title{
STRAMONIUM PSYCHODELIA
}

G. De Young, M.D., DIP. ANAES., C.R.C.P.(c), AND E. G. Cross, M.D., F.R.C.P.(c) $\nmid$

DURING THE PAST YEAR, six cases of stramonium poisoning were seen in the Emergency Department of the Toronto East General Hospital. In all cases the drug had been taken orally by teenagers desiring an experience similar to that seen with other psychodelic drugs.

The historic use of stramonium alkaloids for psychodelic experience is largely confined to the western hemisphere. It was used by the Inca and Chibacha Indians of South America for medico-religious purposes. Preparations containing stramonium are still in similar use by natives of the southwestern United States and Mexico, and by the Jivaro medicine men of South America. These medicine men combine the preparation with alcoholic beverages to bring out hallucinations which are used in turn to diagnose and to prophesy. ${ }^{5}$

\section{Preparation, Use, and Toxicity}

Stramonium is prepared from chopped plant parts of Datura stramonium (jimsonweed), and potassium nitrite is added to enhance its combustibility. It is often adulterated with tobacco, tea leaves, chestnut leaves, and gum benzoin. In North America, for the relief of asthma, the drug is usually smoked either as a cigarette or by direct inhalation by burning it in a dish. For psychodelic purposes however, the drug is usually taken orally by the teaspoonful and washed down with cola.

The alkaloids involved as the active principle have been found on paper chromatography to be atropine, hyoscine, and hyoscyamine. The 150 of one commercially available preparation (Asthamador) with all its adulterants is said to be $6000 \mathrm{mg} / \mathrm{kg}$ body weight. The LD 50 of the potassium nitrite which is used with it is given as $1750 \mathrm{mg} / \mathrm{kg}^{5}{ }^{5}$ This information in our opinion is questionable because one teaspoon of stramonium preparation weighs about $750 \mathrm{mg}$ and the clinical effects are very severe with doses of three or more teaspoons.

\section{Case Reports}

$B . R$. was brought to the Emergency Department by the morality squad with three other juveniles. He had been found on the street picking at the air as well as at various objects he found in the street. Observation revealed an agitated youngster who was having mainly visual hallucinations. He had periods of surprising lucidity alternating with confusion and disorientation and exhibited mild

-From the Department of Medicine, Toronto East General and Orthopaedic Hospital.

†Dr. DeYoung is now on the staff of the Department of Anaesthesia of the Queensway Hospital, Toronto. Dr. Cross is Physician in Chief, Toronto East General and Orthopaedic Hospital. Requests for reprints should be directed to him.

Can. Anaes. Soc. J., vol. 16, no. 5, September 1969 
paranoid delusions. His face was flushed, his pupils were widely dilated, and his skin and mucous membranes were dry and warm. Information was obtained from one of his friends that he had taken stramonium.

The patient was treated with diazepam (Valium, Roche) $10 \mathrm{mg}$ intravenously, pilocarpine 4 per cent eyedrops, and Dilantin $100 \mathrm{mg}$ intramuscularly. Intravenous fluids were given. The patient remained in hospital for twenty-four hours. Diazepam $10 \mathrm{mg}$ was given orally when needed and pilocarpine was used to keep the patient's pupils constricted. Vital signs were observed every 15 minutes. By the time of discharge his symptoms and signs had completely abated.

H.D., a twenty-year-old male, was brought to the Emergency Department by the police. He had been found stumbling a serpentine course on one of the main streets of Toronto with only one shoe on. He could not remember his name and had completely lost orientation as to time and place. His hallucinations included seeing a dog and several of his friends in the examining room. He frequently engaged these friends in conversation and would use their alleged remarks to substantiate his paranoid delusions. He made one attempt to leave the Emergency Department while he was nude. Within several hours he began to realize that his hallucinations were not real, and he became completely lucid within 12 hours. He stated that he had purchased without prescription a one-dollar tin of "Kellogs" (a commercial stramonium-containing compound), and at a party had taken 312 teaspoonsful of the leaves. He claimed that the hallucinations were more vivid than those he had experienced with LSD, but he could not remember details of them or what had happened between the party and the hospital.

\section{Discussion}

Stramonium preparations are just another addition to a large number of drugs used by thrill-seeking youths. These include volatile inhalants such as ether, glues, gasoline, nail polish remover, and cleaning fluids; stimulants of the amphetamine group; and the hallucinogens, marijuana, hashish, LSD (lysergic acid), and STP (2,5-dimethoxy 4-methyl amphetamine). More recently drug combinations have become popular-amphetamines and hallucinogens taken orally or marijuana and stramonium put into the same cigarette. A further addition is dimenhydrinate (Gravol, Horner) in doses exceeding $400 \mathrm{mg} .{ }^{9}$ Catnip for oral ingestion or for cigarette smoking is also becoming popular.

The symptoms and signs of overdose of stramonium as well as individual belladonna alkaloids have been divided into two groups by $\mathrm{D}$. Giacomo ${ }^{6}$ and are well discussed by many authors. ${ }^{1,3,4}$ These include the acute brain syndrome and the physical effects of anticholinergic drugs.

1. The acute brain syndrome, which occurs 30 to 60 minutes after ingestion includes: (a) confusion and disorientation, $(b)$ ataxia and slurred speech, $(c)$ alternating periods of lucidity and agitation, $(d)$ extreme sensitivity to peripheral activity with mis-identification of people, $(e)$ thought disorder-paranoid thinking, hallucinations of auditory, visual, and touch sensations.

2. Physical effects of anticholinergic drugs include (a) flushed colour, (b) 
warm, dry skin, $(c)$ dry mouth and mucous membranes, $(d)$ elevated temperature, $(e)$ dilated pupils, $(f)$ tachycardia, bounding pulse, and/or palpitations.

Treatment of stramonium poisoning is similar to treatment for atropine overdose. In most cases conservative management is the treatment of choice. The therapy at this centre has been mainly confined to the relief of the acute brain syndromes and is similar to our treatment of LSD abuse. ${ }^{7-9}$ So far we have found that the side effects of stramonium in the dosages taken do not interfere enough with the patient's basic physiology to warrant the use of anticholinesterase such as neostigmine. Meiring noted in his cases that neostigmine was of little value. ${ }^{2}$ Our regime is not directed at the hallucinations per se. Our aim is to relieve acute agitation through helping the patient to accept his hallucinations.

One must also prevent the patient from doing harm to himself during his confused state. This entails constant observation. Diazepam seems to be the best drug in this situation. ${ }^{7,8}$ To calm the patient, however, it must be combined with almost continual nursing supervision by a team that approaches the confused youth quietly and with a degree of sympathy. ${ }^{9}$

Diazepam is initially given intravenously to a maximum of $50 \mathrm{mg}$ slowly over 15 minutes. The pulse, blood pressure, and respiration must be closely monitored. Hypotension and respiratory depression may occur with too rapid administration. ${ }^{8}$ After the initial intravenous dose, the drug is given in $10 \mathrm{mg}$ doses orally every four to six hours. This dose may be doubled in severe cases.

Phenothiazine tranquilizers such as chlorpromazine and even perphenizine (Phenergan, Poulenc) are contraindicated in treatment of these overdoses because they themselves also have antimuscarinic side effects and therefore have an additive effect. Because of the recent practice of mixing drugs and because of the antimuscarinic action of some drugs like STP, it is unwise to consider phenothiazines for any case of hallucinogenic drug abuse. Other sedatives such as paraldehyde and phenobarbital have been widely used, but do not seem as effective as diazepam.

Miotic solutions seem to be mainly for symptomatic relief of the mydriasis and cycloplegia. High volume intravenous therapy ( $10 \mathrm{~L}$ daily) may be useful, but it is nearly impossible to maintain an intravenous catheter in these very agitated patients. Little can be gained by lavage once the hallucinations have begun. ${ }^{2}$

\section{SUMMARY}

The psychodelic actions of anticholinergic drugs has been reviewed. The compound of reference is stramonium. A history of use as well as the toxicology have been discussed. The best method of treatment at present seems to be intravenous diazepam followed by oral doses of the same drug. Phenothiazine compounds are contraindicated.

\section{RÉSUMÉ}

Nous avons étudié de nouveau les effets psychodéliques des médicaments anticholinergiques. Le stramonium est le composé qui sert de point de comparaison. 
Nous avons discuté sa toxicologie et l'histoire de son usage. Pour le moment, le meilleur traitement semble être le diazepam par voie endoveineuse suivi de doses par os du même produit. Les composés de phénothiazine sont contrindiqués.

\section{REFERENCES}

1. Koff, Marvin. Poisoning from Ingestion of Asthma Powders, J.A.M.A. 198: 1034 (1966).

2. Menring, P. DE. V. Poisoning by Datura Stramonium. South Africa M. J. 40: 311 (1966).

3. Textelbaum, D. T. Stramonium Poisoning in Teeny-Boppers, Ann. Int. Med. 68: 174 (1968).

4. Cummencs, B. M.; Wrison, M. R.; \& Obetz, S. W. Belladonna Poisoning as a Facet of Psychodelia. J.A.M.A. 204: 1011 (1968).

5. Tramontana, J. A. \& Der Marderosian, A. H. Anti-Asthmatic Drugs as Hallucinogens. Pennsylvania Med. 70: 58 (1967).

6. D. Gracomo, J. N. Toxic Effect of Stramonium Simulating an ISD Trip. J.A.M.A. 204: 265 (1968).

7. Solursh, L. P. \& Clement, W. R. Hallucinogenic Drug Abuse. C.M.A.J. $98: 407$ (1968).

8. Solvish, L. P., et al. Use of Diazepam in Hallucinogenic Drug Crisis. J.A.M.A. 205: 644 (1968).

9. UNwIN, J. R. Illicit Drug Use among Canadian Youth. C.M.A.J. 98: 402 (1968). 